\title{
"SOCIO-ECONOMIC STATUS OF AETAS IN THE PROVINCE OF ZAMBALES, PHILIPPINES: BASIS FOR A PROPOSED SUSTAINABILITY PLAN"
}

\author{
Roel Palo Anicas ${ }^{*}$ \\ ${ }^{1}$ Dean, Institute of Graduate Studies ${ }^{1}$ Director, Quality Assurance and Accreditation ${ }^{1}$ Gordon College, Olongapo City, Philippines \\ *Corresponding Author:anicas.roel@gordoncollege.edu,ph
}

\begin{abstract}
:
Indigenous tribes are said to be the living treasures of a country. The study aimed to determine the relationship of the Aetas with other residents in the community. Qualitative method of research using Photovoice, interviews and observation through FGD among 729 families were used.The following are the themes: 1) The Longing for the Sense of Belongingness as Part of a Community - “Am I welcome to this place?"; 2) Noblest Task as a Member of the Community; 3) Leverage on Sound Interpersonal Relationship; 4) Willingness to Success and Avoidance of Discriminations - "Am I belong?"; and 5) New Hopes, New Aspirations, New Life ... "Unwavering Support from Stakeholders". The following were the findings: they felt that discrimination exists; there's willingness to help and support the community; there are conflicts between their co-Aetas but settled righteously; and there are groups of NGOs, Government Agencies, or Private Companies extending help, and aids in the community. It is concluded that discrimination exists in the community and occurrences of conflicts among them and with neighbors who are "unat"; and overflowing supports extended to them from different organizations extending help and aids. It is recommended that the ROEL Integrative Scheme for Sustainability Development must be implemented.
\end{abstract}

Keywords

Social Science, indigenous tribes, Aetas, sense of belongingness, qualitative research, ROEL Integrative Scheme for Sustainability Development, Province of Zambales, Philippines

Article Received: 18 October 2020, Revised: 3 November 2020, Accepted: 24 December 2020

\section{INTRODUCTION}

The 1987 Philippine Constitution categorically states that the State shall promote the rights and welfare of the indigenous tribes in the country. Thus, the Indigenous Peoples Rights Act (IPRA) or RA 8371, legislated in 1987, recognizes the unique cultures of the indigenous tribes and enumerates their rights including their right to ancestral domain (Casambre' ${ }^{\mathbf{1}}$,2006: 105-119).

In his paper, "Who are the Indigenous? Origins and Transformations," Dr. Lawrence Reid (2008), a New Zealand -born researcher emeritus of the University Hawaii says that the numerous Negrito tribes in the Philippines are on the brink of extinction because of the massive acculturation which could probably result to complete assimilation. Dr. Reid recommended a thorough study of the immediate needs of the tribal people and an urgent action to help them survive.

If we aim to understand humans, it is essential that we study them at all times and places. We must not only study ancient humans, but modern humans as well. We must study their cultures and their biology. For how can we understand what is truly human in general or the way humans vary from one another? If we study only our own society, we may come up with limited explanations that are culturally bound and not generally applicable to all human beings.

In Dr. Reid's presentation about the Negritoes, he made a strong recommendation on the need to engage in a thorough research in connection to which, this proponent remembered his experience with an Aeta quack doctor (albularyo) in Baguio City, twenty-three years 
ago. Questions were lingering in his mind questions that demanded for answers, like, "How are the Aetas people copping up with the demands of the times?" and "How are they treated by their surrounding neighbors?" Consequently, the said proponent visited the Aetas community last February 2016, December 2017 and February 2018 for Community Extension Services specifically on conducting literacy program, health teaching and gift giving.

A study focusing on the unique culture of the Aetas is important as it is relevant because it helps in the understanding of fellow humans. The findings of this research should make people understand why the Aetas are different from us. Readers may then come to realize that the many differences between peoples are by products of physical and cultural adaptations to different environments.

The impetus of change may come from within society. But cultural evolution may be stimulated by changes from the external environment, like, a tribe's change of settlement. With regards to the Aeta communities in Barangay Sta. Maria, Palauig; Barangay Dampay, Palauig; Sitio Belbel, Iba; Sitio Lakas, Botolan; Sitio Moraza, Botalan; Sitio Cawag, Subic; Sitio Lumibao, San Marcelino; Sitio Yangil, San Felipe; Barangay Paite, San Narciso; and Sitio Maporac, Cabangan in the Province of Zambales, these people experienced changes both in physical and social environments. Ember ${ }^{2}$ (2002: 319322)concluded that radical changes have resulted to the modification of the shared behaviors, beliefs and values of the many ethnic groups in the world.

The proponent's personal experience with the Aetas has proven helpful in his profession and teaching. However, he still feels that there is a pressing need to engage in a deep study so that the Aetas unique socio-economic status will truly be documented. In this way, the simple yet interesting status of the Aetas will be shared to others more meaningfully.
Personally, the heart moving condition of the Aetas folks motivated the proponent to engage in this research.

\section{METHODOLOGY}

The design used in the investigation of the study is mixed quantitative and qualitative method of research.

The quantitative aspect using descriptive survey method of research was used in this study. The variables considered were the settlement formation, dress and personal adornments, social traits, and economic activities of the participants.

The qualitative aspect of the study the data were collected and analysed using photovoice and in-depth interview and observation utilizing Focus Group Discussion (FGD).

Photovoice is rooted in Paulo Freire's pedagogy of critical consciousness which empowers the common people to become agents of positive change in their communities. Data are generated through photography. The participants are documented with their realities. The assumption in photovoice is that pictures "are worth a thousand words" and that reality cannot be denied by policymakers when they start at it at the face. Photovoice is usually used with participants whose voices are silenced through marginalization and oppression. Among these groups are children, women, and cultural minorities.

This study was conducted in Province of Zambales specifically in Barangay Sta. Maria, Palauig; Barangay Dampay, Palauig; Sitio Belbel, Iba; Sitio Lakas, Botolan; Sitio Moraza, Botalan; Sitio Cawag, Subic; Sitio Lumibao, San Marcelino; Sitio Yangil, San Felipe; Barangay Paite, San Narciso; and Sitio Maporac, Cabangan in the Province of Zambales.

The study was conducted in this province because the covered areas of the ten (10) Aeta communities are situated in the different Sitios, Barangays, and Municipalities in the Province of Zambales, respectively. These are the Aetas who were relocated by the Provicial Government of the 
Province of Zambales right after the $1991 \mathrm{Mt}$. Pinatubo eruption.

The research used unstructured questionnaires and made used of photovoice and iterative interviews and observations during the immersion; respectively.

Part I solicits the socio-economic status of the respondents such as the settlement formation, dress and personal adornments, social traits, and economic activities.

Part II of the questionnaire is an unstructured question on the relationship of the Aetas with the non-Aetas residents.

The survey-questionnaires were translated in Filipino for the participants to better understand each parts and content of the instrument. It was translated in Filipino not with their dialect Zambal Tina or Zambal Aeta because the researcher could not facilitate properly using the said dialect.

The researcher chose five (5) experts. They are holders of Doctorate degree in Education and Philosophy. They were experts in the field of qualitative research and college and university Professors from University of Luzon in Dagupan City (Pangasinan), Laguna State Polytechnic University - Siniloan Campus in Laguna, De La Salle University-Dasmarinas City, Cavite, Holy Name University in Bohol and Bataan Peninsula State University in Bataan.

Result of the validation on the survey questionnaires has a mean score of 5.0 described as excellent.

Frequency and percentage distribution were used to analyze the socio-economic status of the Participants.

Data drawn transpired using Photovoice and interviews and observations utilizing Focus Group Discussion (FGD) was also analysed using thematic analysis.

The conduct of the study was approved by the National Commission on Indigenous Peoples Regional Office III in San Fernando City Pampanga and it was awarded a Certificate of Pre Condition that proves that the study conducted does not violates the Indigenous Knowledge
Systems and Practices (IKSPs) and Customary Laws of the respondents.

\section{RESULTS AND DISCUSSION}

Part One, Descriptive Analysis, presents the frequency and percentages which were used to determine the responses of the participants on the Socio-Economic Status of Aetas in the Province of Zambales when taken as a whole and when grouped as to settlement formation, dress and personal adornments, social traits, and economic activities.

Part Two, the Qualitative part of this study presents the views of the participants on their relationship with non-Aetas residents in the community.

\subsection{Descriptive Analysis}

\section{Socio-Economic Profile of the Respondents}

\section{A. Settlement Formation}

The responses of the participants on their Settlement Formation such as: housing tenure; length of stay in the residence; house type; housing materials; lighting; cooking fuel; appliances/amenities used by the household; main source of drinking water; toilet facility used at home; and estimated daily expenses in Peso (Php).

\section{Housing Tenure}

Private property determines the socioeconomic status of an individual, his or her capacity to sustain a shelter, and the situation and priorities in his or her career.

It appears that out of the seven hundred twenty-nine (729) respondents, those who own house and lot shows dominance with six hundred eighteen (618) respondents, having $84.77 \%$ of the total population while twenty-seven respondents or $3.70 \%$ own house only. However, eighty-four (84) or $11.53 \%$ of them are informal settlers. This indicates that many of them already own both house and lot while there are still quite a number of respondents who resides in houses which are not theirs. 


\section{Length of Stay in the Residence (in years)}

Length of stay in the residence is distinguished as an indicative to maintaining and overcoming the status quo of an individual, may it be affected via economic or physical stability of the residential area itself.

The distribution of respondents based on their length of stay in the residence. This shows that six hundred seventy-eight (678) or $93.00 \%$ of the total respondents stayed in their residence for 27 years already while there are only fifty-one (51) or $7.00 \%$ who stayed in their residence for 25 years. This indicates that most of them already have the capacity to live in their residences through the year despite of their status quo.

\section{House Type}

The type of house that residents own or have demonstrates the kind of living they are into, may they be contented to be isolated, in its sense, in a single detached house, residing with a row house type, or due to economic status, in a make shift house.

The grouping of respondents according to the type of house they are currently residing. This shows that six hundred eighteen (618) respondents or $84.77 \%$ of the total population live in makeshift house type. Twenty-seven (27) or $3.70 \%$ of them live in a row house type while there are eighty-four (84) or $11.53 \%$ of the total respondents reside in a single detached type of house. This indicates that many respondents maintained to reside in a single detached house type while there are residents who are contented or continued to live in row house or make-shift because of their economic status or their preference.

\section{Housing Materials}

Available resources and individual preference determine the materials used in building houses. Resources differ whether the residents are living in an urbanized area, rural, or remote areas. Preferences differ depending on their financial capability and the needs or wants for the total protection, security, and safety or their shelter.

This shows that a dominant number of respondents used "Pawig" and "Nipa" on their housing materials with four hundred (400) or $54.86 \%$ of the total population. Two hundred eighty-nine (289) of the respondents or $39.64 \%$ used semi-permanent housing materials such as wood, hollow blocks, and G.I. roofing while there are only forty (40) respondents or $5.50 \%$ who used permanent housing materials such as hollow blocks, concrete, and G.I. roofing. This indicates that only a few of them used permanent housing materials and most of the respondents used "Pawig" and "Nipa" for the stability of their houses.

\section{Lighting}

The type of lighting the residents have in their houses determines the capability of individuals to supply an efficient lighting, depending on their economic status in providing for the consumption of electricity or depending on the reachable electricity range or their preferences.

Three hundred twenty-nine (329) or $45.13 \%$ of the total respondents have electricity as their lighting while three hundred twenty (320) or $43.87 \%$ use kerosene as their lighting. However, eighty-two (82) respondents use emergency lights. This indicates that many respondents are financially capable to use electricity and prefer using kerosene as their source of light in their houses, while taking into consideration that there are still residents who use emergency lights eitherto conserve energy or budget.

\section{Cooking Fuel}

Type of fuel using in cooking ascertains the preference of an individual and the resources available near their residential area.

There are three hundred eleven (311) or $43.65 \%$ of the total respondents use LPG as their cooking fuel while two hundred eighteen (218) or $30.00 \%$ use wood and one hundred sixty-one (161) or $22.09 \%$ of the respondents use charcoal. However, twenty-three (23) or $3.16 \%$ of the total 
respondents use gas or kusinilya as their cooking fuel and only eight (8) or $1.10 \%$ use electricity. This indicates that many respondents are used to or preferred to use the usual LPG, traditional wood and charcoal than gas and electricity as their cooking fuel.

\section{Appliances / Amenities Used by the Household}

Electric consumption and monthly electric bill are determined by the frequency and quantity of appliances / amenities used in a certain household.

This shows that mobile / cellular phone is ranked as the most used with six hundred eightyfive (685) respondents, followed by LPG stove with three hundred eleven (311), and electric fan with two hundred eighty-seven (287). However, there is only eighteen (18) who use laptop, sixteen (16) who use personal computer, and fourteen (14) who use stereo / component.

This indicates that mobile / cellular phones are very much important for the respondents, may it either be in terms of communication or for news updates.

This is a good indication that Information and Communication Technology (ICT) has been part and parcel of their lives in learning new information as far as technology is concern. Technological advances have reshaped the size and nature of the industry, allowing it to extend beyond the traditional.

It is noticeably that 685 families out of 729 is a strong indicator that $94 \%$ of the families have the knowledge to manipulate and used this type of amenities or gadget as a by-product of the advancement of technology. This is one way to further explained that despite of their status in the community they were able to purchased such amenities in their household/families as a great means of transmitting, collecting, and exchanging messages, new knowledge and information among themselves and in the community. In this regard, they are not left behind as to the new trends and technology that are uprising in the community.

\section{Main Source of Drinking Water}

Main source of drinking water is acquired through the available resources near the residential areas of the individuals.

Of the seven hundred twenty-nine (729) respondents, three hundred sixty-eight (368) or $50.48 \%$ of them get their main source of drinking water from "sibul" or spring while one hundred nineteen (119) or $16.32 \%$ get from deep wells and one hundred thirteen (113) or $15.50 \%$ get from pumping or "gripo". However, there are eightyone (81) or $11.12 \%$ of the respondents who acquire drinking water from the river water as their main source while there are forty-eight (48) or $6.58 \%$ who acquire from Nawasa. This indicates that many respondents depend on sibul or spring as their main source of drinking water while there are only few who can acquire from Nawasa.

\section{Toilet Facility Used at Home}

Water consumption and domestic budget allocation come together with regards to toilet facility used at home, depending on their capability to provide.

This shows that four hundred sixty-two (462) or $63.37 \%$ of the total respondents use hand flushed toilets while there are only two hundred sixty-seven (267) or $36.63 \%$ who use water flushed toilets. This indicates that more than half of the total respondents were not able to have water flushed toilets at their homes and it could be a concern on domestic budget allocation

\section{Estimated Daily Expenses in Peso (Php)}

Daily expenses are determined through their basic needs on the day-to-day basis where budget acquired also figures out their status quo.

Three hundred ten (310) or $42.54 \%$ of the total respondents spend below Php 100.00 daily while there are ninety-eight (98) or $13.43 \%$ who spend more than Php 250.00 daily. This indicates that there are varying levels of daily expenses, depending on the basic needs that every household must meet. 


\section{$\underline{\text { B. Dress and Personal Adornments }}$}

The data clearly shows that all of the respondents are capable of purchasing brand new dresses, especially the school uniforms of their children.

It also reveals that six hundred thirty-six (636) or $87.24 \%$ do not use "G-string" and "Tapis" made of indigenous materials such as the bark of trees and thin fabric-like material of young coconut palms and commercial cloth as their dress or personal adornments. Six hundred eighty-seven (687) or $94.24 \%$ of them never appear wearing traditional dresses and adornments yet wear those during cultural presentations or during town and provincial fiestas only.

Meanwhile, there are almost half $(49.66 \%)$ of them who buy second-hand dresses called "ukay-ukay" from the town market while there are $50.34 \%$ who do not.

It can be implied that the culture of Aetas in terms of clothing are still preserved but dominantly, common or usual clothing are being used nowadays as their personal adornments.

\section{Social Traits}

Values, morals, attitude, and socialization determine the social character traits an individual possesses in a certain situation or scenario.

Among the seven (7) Positive Attitudes they possessed the following are the ranked, to wit: being Cooperative (Rank 1); being Resourceful (Rank 2); being Kind (Rank 3); being Honest (Rank 4); being Considerate (Rank 5); being Friendly (Rank 6); and being Reliable (Rank 7; respectively.

On the other hand, on the Negative Attitudes they possessed the following were ranked accordingly: having the attitude to pull down others or the crab mentality (Rank 1); being Cruel (Rank 2); being Dishonest (Rank 3); being Unreliable (Rank 4); beingAloof/Unfriendly to others (Rank 5; being Inconsiderate (Rank 6); and being Lazy (Rank 7).

Reliable. They have the audacity to give unbiased yet plausible information such as, but not limited to, Aeta residents who are aware of the situations happening in their community.

Unreliable. Sometimes they give differing information, contradicting various aspects such as, but not limited to, when a resident is giving opinionated facts and is unsure of some statements.

Kindness. They show humanity at heart and gives unsolicited actions such as, but not limited to, serving his or her co-Aetas with utmost respect and due diligence.

Cruelty. When an individual possesses inhumane interactions and invalidates the work of another such as, but not limited to, disintegration, discrimination, and being rude.

Honesty. They shows apathy and sympathy to every work, may it be a success or a faulty one such as, but not limited to, admitting humbly his or her wrongdoings.

Dishonesty. Aetas are threatened to hide a faulty work such as, but not limited to, stating the positive rather than the truth.

Considerate. They looks into the potentiality of one person without discriminating his or her capability such as, but not limited to, being acceptable to what can one do in a given amount of time in work

Inconsiderate. They debilitate the capability of one person to improve such as, but not limited to, having strict standards and being discriminatory when one could not meet the standards.

Friendly. Most of them interacts with kindness and politeness to any person he or she is socializing with such as, but not limited to, showing respect and being open to who they are when one is socializing.

Aloof / Unfriendly. Some of them interacts with biased personality, selecting persons whom to socialize with such as, but not limited to, being kind to one but shows cruelty to another.

Cooperative. They cooperate into the oneness and unity for the welfare of the entire tribe or community such as, but not limited to, participating actively to the programs and projects that are beneficial for all. 
Crab Mentality. Some of the Aetas possesses a mentality wherein inferiority over the capability of others dominates such as, but not limited to, the mentality of when one cannot do a certain task, others cannot do also.

Resourceful. They think or make ways which are feasible for a certain concern or issue such as, but not limited to, providing innovative ways to conserve energy.

Lazy. Some are unwilling and unable to do productive work with his companions such as, but not limited to, tardiness, uncooperative, andunproductiveness.

\section{Economic Activities}

The results shows that farming, may it be planting rice, root crops, vegetables, banana, or others, is ranked as the topmost economic activity of Aetas with six hundred eleven (611), followed by selling of organic products such as root crops, vegetables, and fruits with three hundred seventyone (371), and the hunting of animals and trapping of birds and fowls with two hundred eighty-one (281).

It also reveals that eighteen (18) Aetas manage sari-sari store and only fourteen (14) enjoy being a tourist guide, ranked as ninth and tenth, respectively.

It can be implied that farming is the top economic priority of the Aetas for their living while being a tourist guide serves as an interesting economic activity for the few.

\subsection{Results of the Qualitative Study}

This portion of the study presented the different views, responses and perspective of the participants on their relationship with non-Aeta residents in the community where they belong.

Data was gathered through the use of structured survey-questionnaires and unstructured questionnaires applying the iterative interviews and observation through the conduction of Focus
Group Discussion (FGD) among the respondents of the study and Photovoice.

An iterative interview was conducted among the ten (10) Chieftains of the Aeta communities in the Province of Zambales.

Photovoice was used during observation in the Aeta communities and outputs were presented through documentary photographs.

The following are the criteria that were considered in the interviews conducted, to wit:

1. Their ancestral domains are in the mouth of Mt. Pinabutubo;

2. They lived in small villages on the foot of the volcanovolcano;

3. They are all victims of the Mt. Pinatubo eruptions way back 1991;

4. They are pure Aetas and resident and local of the Province of Zambales;

5. They are able to speak both Zambal Aeta and Zambal Tina, respectively; and

6. They are very much willing to participate in the conduct of the study.

The names of the chieftains per Aeta communities, wherein there are seven (7) males, only one (1) female and three (3) other communities are being led and supervised by the Local Government Unit (LGU) of the concerned municipality.

Mr. Benny Pulagay in Sta. Marta, in Palauig; Mr. Joseph Badar in Dampay, Palauig; Mr. Atanacio Carino in Sitio Belbel, Iba; Mrs. Fe Balbin in Sitio Lakas, Botolan; Mr. Doming Cabali in Sitio Moraza, Botolan; Mr. Ernesto Solomon in Sitio Cawag, Subic; Sitio Lumibao,in San Marcelino, Sitio Yangil, in San Felipe, and Paite,in San Narciso were led by the Local Government Unit headed by the Municipal Mayor with the cooperation of the Municipal Social Welfare and Development Office and Municipal Health Unit; and Mr. Jerome Dalit in Sitio Maporac, in Cabanggan, Zambales; respectively. They are selected through selection process with the presence of the Barangay Councils and with the supervision of the Municipal Officer of the Department of Interior 
and Local Government. Majority of them has been serving their respective communities for not less than ten (10) years.

\section{Relationship of the Aetas with the Non-Aeta Residents}

There are five (5) themes to present the responses gathered during the iterative interviews with the Chieftains and lead groups and Focus Group Discussion (FGD) among the selected participants of the populace in the Aeta communities.

The following are the themes that were analyzed that corresponds the questions that were asked among the informants:

1. The Longing for the Sense of Belongingness as Part of a Community - "Am I welcome to this place?"

2. Noblest Task as a Member of the Community

3. Leverage on Sound Interpersonal Relationship

4. Willingness to Success and Avoidance of Discriminations - "Am I belong?"

5. New Hopes, New Aspirations, New Life ... "Unwavering Support from Stakeholders"

\section{The Longing for the Sense of Belongingness}

as Part of a Community - "Am I welcome to this place?"

The promise of a more stable source of income, better status of their life, drove many Aetas lived in small villages on the volcano to pack their things and resettle in the different resettlement areas given by the Provincial Government of the Province of Zambales and the different Municipal Government officials.

Their families are new in the community and the application to adopt not only with the place but as well as with the community-folks who lived longer than them.

Their difficulty in dealing with their nonAeta resident has been felt all of them during their first settlement in the place.
[The very first time we arrived here, it seemsthat they don't like us. Our parents are telling not to fight for them wherein we need to be good with them because we just migrated in this place.]

(Crying while narrating the story.) P12

[There is the feeling of discrimination. And it seems that we are not welcome in their place.]P23

II even told to my parents to return and lived nearby the volcano. A silent place and to live a simple life and we were used to stay there already.] P 41

According to conducted researches, "selfpitying persons are characterized as likely to overindulge in their failures, hardships, and losses, and the circumstances elicited by these setbacks, thus becoming self-consciously preoccupied with their own suffering" (Charmaz, 2002). ${ }^{3}$ Nevertheless, "self-pity is not an emotional response directed exclusively towards the self. Whereas the primary focus in self-pity may be on the self, self-pity also has a strong interpersonal component. Quite often, self-pity is an emotional response directed towards others with the goal of attracting attention, empathy, or help". Clinical observations suggest that individuals who experience self-pity usually expect more from the environment than the environment is willing to give. Personal relationships are perceived as unstable and characterized by high demandingness on the part of the person who experiences self-pity, and who sees his or her environment as unwilling to provide the empathy, comfort, and support him or her demands. Consequently, a person who feels self-pity is permanently frustrated. This permanent frustration with others may have two consequences. First, it may lead to social withdrawal and feelings of loneliness (Charmaz, 2002). Second, it may lead to feelings of aggression, hostility, and anger; However, open displays of aggression, hostility, and anger are in conflict with the aims of attracting empathy, support, and acknowledgment from others. 
Individuals with susceptibility for self-pity often are characterized by great self-insecurity. Thus, they may lack the self-assertiveness needed to confront others openly. As a consequence, the direct expression of aggression and hostility will be inhibited. Only mild forms of anger will be expressed, whereas strong anger will be suppressed, turned inward, or even turned against oneself). Under the surface, however, the anger against others will continue to exist, often accompanied by ruminations about retributions for the past. Self-pity clearly falls into the class of ineffective coping strategies that are more likely to exaggerate a problem and create new difficulties than to help deal successfully with stressful situations. The present findings confirm observations reported in the clinical literature that self-pity is related to loneliness. However, as the two-dimensional conceptualization following Russell, D.,Cutrona, C.E., Rose, L,. \& Yurko, K. (1984) (1984)" "typology of loneliness showed, self-pity was related only to emotional loneliness, but not to social loneliness, in line with the clinical literature and previous findings, the present findings show that self-pity is closely related to depression, even when common variance with gender and other facets of neuroticism are controlled for."

\section{Noblest Task as a Member of the Community}

Cooperation and mutual understanding between and among the members of the community is dynamic in the different Aeta communities. The populaces are all active and cooperative in the realization of their activities, projects and programs being conducted and implemented in their community. As far as Rural Community Development is concerned they are much willing to share and contribute not only their resources but their strengths in the realization of their activities respectively.

[We are following our Chieftain because this is for our betterment. In just simply following the policies here in our place it is already a big contribution for our own development.]P27

[We are participating in th different Programs, projects, and activities of our community.]P22

[I am attending meetings and assembly here in our community. I am enlightened with the responsibilities each must be doing and following in our community.]P4

[I am willing to share with my neighbors all knowledge and information I have learned from attending seminars and workshops on how to prepare processed foods, the proper ways and means of food preservations, and on how to maintain good hygiene and health.]P20

With their testimonies, it is a great manifestation that as a member of their respective communities they have the sense of responsibility, open for change and development, and willing to share their knowledge, skills and talent for the betterment of their community as a whole.

\section{Leverage on Sound Interpersonal Relationship}

Positive and sound interpersonal relationships will allow effective communication and understanding among persons in a community to be able to understand each other.

There are associations Aeta families in the different Aeta communities. Some are active member of the Born Again Christian Congregation and became one of the dividing issues within the Aeta community. But there are occasions wherein each member has some conflicts. But most of the time within themselves problems are being solved. Each lived happily and even shared some of their foods, and among others.

[We are united in all the projects in our community.]P41

[We are helping each other.]P25 
[We are a family. We are faithful with our Savior.]P38

It is evident that through their statements despite and in spite of sometimes they have misunderstanding and conflict the following has been noticed between and among themselves in their community such as: they are showing respect among others, they are honest, they have an open communication, and they are always positive and maintains boundaries, and able to manage their emotions.

\section{Willingness to Success and Avoidance of Discriminations - "Am I belong?"}

During the FGD and interviews of the key informants, they have promising responses and they are open-minded and very much willing to extend their services most especially if this is for the development of the community where they belong. But they are ascertaining if they are really accepted in the community considering most of them especially the elders cannot able to read and write, was not able to finish a degree, and just an extra-ordinary individual in the community but they are very much willing to participate and be a part and parcel of all activities in the community with the "unat".

[We don't want to fight especially to those not like us having a curly hair. We are appealing if possible they will not call us an Ita or havinga curly hair.]P35

[We are respecting them, so they must dothe same.]P2

[We are ready to join and participatein all the plan projects in our place.We are just here when they need us for help. But since we don't have theresources it is just our strength thatwe can extend because what we profitedfrom the field are not even enough

for our daily expenses in our family.]'P15
With their responses, the Aetas have laid their cards that they are very much willing to extend they helping hand, join and participate in every activities provided they will be respected, they will be treated as if they are not "Ita" or "kulot".

According to Tambunan (2014), ${ }^{\mathbf{5}}$ a counselor, she pointed out that " $a$ sense of belonging simply means an acceptance as a natural member of something. If we talk about this, it means that a sense of belonging provides a close and secure relationship. I can see that happiness is involved there. To begin my analysis, I'd like to say that, dear readers, this is about acceptance and happiness which are two things that make us human. Basically, they will drive us to do something. You know, even a schizophrenic trait could spring out by denial: it is that acceptance-absence situation, towards its patient. Wherein a pervasive human concern is establishing and maintaining relatedness to others, social institutions, environments, and the self. One component of connecting one's self into the fabric of surrounding people, places, and things is a sense of belonging.

Furthermore, Anicas (2012) ${ }^{\mathbf{6}}$ said that " $a$ sense of belonging is a sense of personal involvement in a social system so that persons feel themselves to be an indispensible and integral part of the system."

\section{New Hopes, New Aspirations, New Life "Unwavering Support from Stakeholders"}

There are groups of Non-Government Organization (NGO), Government Agencies and Private Companies extending help, aid, activities, projects, and programs in the different Aeta communities.

The following are the NGOs, Government Agencies and Private Agencies extending their supports in the following Aeta communities, to wit: in Barangay Sta. Maria and Barangay Dampay,in Palauig, DAR, DA, DTI, San Miguel Food Corporation and LGU Palauig are helping 
them to further develop their small-scale business such as making brooms, farming crops, seasonal fruits and vegetables, respectively. San Miguel Food Corporation even extended the dispersal of "saso" chicken among the community in cooperation with the Department of Agriculture. And with the support of the Department of Trade and Industry, their brooms have been transported in Baguio City and in Metro Manila. The Department of Agrarian Reform is extending their help among the Aeta communities in Sitio Belbel, Iba on their concerns on their rights on the parcel of lands there are using for the plantation of their rotation crops such as root crops, corn, rice, banana, pineapple, and different types of vegetables; in Sitio Lakas and Sitio Moraza in Botolan,the Department of Agrarian Reform was able to claim the rights to own the parcel of lands their cultivating which let them stay in the community; in Sitio Cawag, Subic, being help by RP Energy which is a power plant located on Redondo Peninsula within the Subic Bay Freeport Zone in Barangay Cawag, Subic, Zambales southwest of the existing Hanjin Shipyard. With the support from RP Energy it is noticeably that this Aeta community is far more developed compared of the other communities. The Sitio Lumibao, San Marcelino and Sitio Maporac, Cabanggan; both communities are being supported by People's Recovery, Empowerment and Development Assistance (PREDA) Foundation. PREDA Foundation are a team of Filipinos that are giving freedom and a new lease of life to girls rescued from the streets, brothels, human traffickers and sex offenders and pedophiles. They are rescuing young boys fifteen years and younger from government detention cells where they are bullied and physically and sexually abused and suffer sub-human conditions on little food and deprived of their children's rights. They are teaching the children specifically on the development of their values and attitudes through series of dynamics and lectures, respectively. In Sitio Yangi in San Felipe and in Barangay Paite, in San Narciso, DTI and their respective LGUs are helping them to further develop their products being sold in the One Town One Product (OTOP) Pasalubong Centers of both municipalities.

[We are extending our gratitude to DTIfor teaching us on our small business and for organizing and inviting us to sell our products in Trade Fairs.]P38

[We were not left behind by the Department of Agrarian Reform for our rights especially with our parcel of lands. $] \mathbf{P 4 7}$

IIt is a big help the support from RP Energy. Our children able to attend their schooling because of their Scholarship Grants.]P6

[It is because of the Department of Agriculture, we were given the chance to further enhance our knowledge about Organic Farming especially the trainings we acquire in UP Los Banos.]P34

"In this view, happiness emerges from a cognitive evaluation that draws on socially constructed standard of the good life. Another theory holds that we rather infer happiness on the basis of how well we feel most of the time. In that view, happiness is an unreasoned affective experience that roots in the gratification of universal human needs" as pointed out by Rojas and Veenhoven (2011). ${ }^{7}$

In the study of Yetim, N, \& Yetim, U.; $(2014)^{\mathbf{8}}$ entitled "Sense of Community and WellBeing: A Research on Fulfillment of Needs and Social Capital in the Turkish Community" it was clearly presented that the "fulfillment of needs and variables of social capital significantly predict sense of community and individual well-being". Wherein in case of the Aeta communities in the province of Zambales, they were fulfilled with the supports of the NGOs, Government Agencies and Private Companies for the help, aid, activities, projects and programs being extended to them, respectively. 


\section{CONCLUSIONS}

The following are the conclusions drawn from the findings of the study:

\section{On the Socio-economic Profile of the}

\section{Participants}

Under the auspices of settlement formation; as to housing tenure they have their own house and lot, a dwelling place safe and sound, comfortable for living despite of some odds in life and able to survive for a simple living.

On their dress and personal adornments; very rare that they are using their traditional dresses, ("G-string" and "Tapis") and these are only worn during cultural presentations; and they are already acculturated.

On the aspect of their social traits; they possess both positive and negative attitudes.

On their economic activities, farming is the major source of their living such as planting rice, root crops, vegetables, and fruits and by selling these products of their hardships to sustain their daily needs in their family.

\section{On the Relationship of the Aetas with the Non- Aeta Residents}

Discrimination exists in the community where they belong. There are occurrences of conflicts between and among them as Aetas as well as with their neighbors who are "unat"; and there are overflowing supports extended to them from the groups of Non-Government Organizations (NGOs), Government Agencies, or Private Companies who are very much willing in extending help, aid, activities, projects, and programs in the community.

\section{RECOMMENDATIONS}

On the basis of the findings and conclusions of the study, the following recommendations are offered:

1. The Department of Agrarian Reform, should further extend their support to the Aetas to strengthen their ownership of the parcels of lands they have; to be given their exclusivity rights of owning their properties as per stated in the Republic Act No. 8371 or also known as the "The Indigenous Peoples Act of 1997" protecting the
Rights to Ancestral Domain, Rights to Ancestral Lands, and among others.

2. The Department of Agriculture should conduct seminar-workshop on managing organic farming to further enhance and develop their skills in farming and assistance must be given and provided to the farmers like quality seeds and seedlings. Another is conducting seminars and training on rotation on inter-cropping, cover cropping, soil management, irrigigation system, organic fertility management, procedure of composting, organic insect management, and involving farmers in sustainable agriculture; respectively.

3. The Local Government Units of the different municipalities wherein the Aeta communities are situated and located, should extend help especially to the farmers in order to solve the problem encountered by the farmers by giving or providing machineries that will make their work faster and to advance their farming activities.

4. The Department of Trade and Industry (DTI) must strengthen their ties among the Aetas in order to further develop their skills in producing quality products that could possibly endorsed for exporting. They must have continuous and varied programs to further support their small-scale products and working hand-inhand with the Local Officials and the Department of Tourism for the promotion of their products in the Pasalubong Centers of the respective municipalities One Town One Product (OTOP) program.

5. That the Department of Tourism must encourage the Aetas to preserve their culture by designing a program that will let the Aetas utilized their traditional clothing and not only during fiestas or cultural presentations. The agency should train Aetas as a Tourist Guide in the different places worth it for a visit and must include in the program the development of Rural Tourism wherein the Aetas will present the sceneries, specialties and products of their groups in their respective Aeta communities. 
6. That the Private Companies such as San Miguel Food Corporation and RP Energy to continuously support, maintain and sustain their projects and programs in the Aeta communities which are a big help for them for the realization of their dreams and aspirations in life.

7. The PREDA Foundation who have been extending a very worthy activities especially to the youth to keep on addressing their needs and on how to further develop their character and values to become a good citizen of the province and to the whole world as well.

8. The proposed Sustainable Development Plan should be presented to the different Local Government Units among the following such as: the Municipal Mayor, the Municipal Planning Officer and as well as with the counterpart of the said offices in Provincial level, for this might be a good basis in planning relevant and appropriate programs for the Aeta communities in their respective municipalities.

9. That the other Government Agencies should extend as well their services like the Department of Interior and Local Government (DILG); the Department of Tourism (DOT); Department of Education (DepEd); Public Attorney's Office (PAO), Department of Public Works and Highways (DPWH), and Department of Health (DOH) for the development and progress concerns.

10. That a copy of this research will be forwarded to the Regional Office of National Commission on Indigenous Peoples (NCIP) in San Fernando City, Pampanga and must be endorsed in the National Office of the National Commission on Indigenous Peoples (NCIP); the Municipal Planning Office of the different municipalities covered in the study; for information dissemination.

11. Studies on the Indigeneous Knowledge, Practices and Systems (IKPS) and Customary Laws of the Aetas in the province must be conducted for proper documentation and to further kept the culture, beliefs, and their practices.
12. Another study maybe conducted to discuss other variables that may affect the implementation of the proposed Sustainability Development Plan named as The ROEL Integrative Scheme for Sustainability Development.

The ROEL Integrative Scheme for

\section{Sustainability Development}

\section{Rationale}

In an ever changing and fast paced corporate world, development plan is indispensable functions. The delivery of trainings which refers to the process of acquiring the essential skills required for development is necessary. It is the reason why, this proposed Sustainable Development Plan has been develop in order to further sustain the socio-economic status of the Aetas in the Province of Zambales.

The proposed Sustainable Development Plan is named as the "ROEL Integrative Scheme for Sustainability Development" anchored with the four (4) Pillars of Sustainability.

The proposed Sustainable Development Plan consists of the following Key Result Area (KRA) to wit:

Responsible Social Enhancement and Administration Dynamics and Empowering their Rights as mandated in the Republic Act No. 8371 or also known as the "The Indigenous Peoples Act of 1987'[Social Sustainability]

Outstanding knowledge on stability of small-scale products for sustainable living and holistic development of the human being[Human Sustainability]

Enhancement of the Technical Knowledge and Skills Development on Organic Farming Economic Sustainability]

Long-term Environmental Sustainable Programs and Projects [Environmental Sustainability]

\section{REFERENCES}

[1] Casambre, Athena Lydia. Indigenous Peoples in Politics and Governance. , in 
Philippine Politics and Governance:

Challenges to Democratization and

Development. Quezon City,

Philippines:2006.

[2] Ember, Carol R. et al. Anthropology. New Jersey Prentice-Hall Inc., 2004.

[3] Charmaz, K., "Stories and Silences: Disclosures and Self in Chronic Illness, SAGE Journals, Volume: 8 Issue 3, pages: 302-328, June 1, 2002; Retrieved from https://doi.org/10.1177/107780040200080 00307

[4] Russell, D.,Cutrona, C.E., Rose, L, . \& Yurko, K. (1984). Social and emotional loneliness: An examination of Weiss's typology of loneliness. Journal of Personality and Social Psychology, 46 (6), 1313-1321. Retrieved from http://dx.doi.org/10.1037/0022-

3514.46.6.1313

[5] Tambunan,Elisabet; Voices of the

Youth.; Retried from

http://www.voicesofyouth.org/en/posts/sen se-of-belonging; Retrieved on October 16, 2018

[6] Anicas, Roel P. Work Motivation and OrganizationalCommitment of the Faculty of the Private Higher Education Institutions (PHEIs) in Region I, Philippines; IAMURE International Journal of Business and Management; Volume 4, No. 1 (2012) October Print ISSN: 2244-1492 Online: 2244-1506

[7] http://search.proquest.com/openview/b462 95d90844b60433769a7df0a7659c/1?pqorigsite $=$ gscholar

[8] Rojas, Mariano \& Veenhoven, Ruut. (2011). Contentment and Affect in the Estimation of Happiness. Social Indicators Research. Retrieved from http://www.110.10.1007/s11205-0119952-0

[9] Yetim, N, \& Yetim, U. (2014). Sense of Community and Well-Being: A Research on Fulfillment of Needs and Social Capital in the Turkish Community. Social
Indicators Research, 115 (1), 93115.Retrieved from http://.jstor.org/stable/2472018 